collector shoes from fixed installations on the track. In general the circumstances of London Transport have favoured fixed track installations called de-icing units, whereby the shoes of every train pass over rollers wetted with a de-icing fluid which is in this way spread along the conductor rail. On the other hand the different requirements of Regions of the Railway Executive have been met by the installation of equipment to spray de-icing liquids either from service trains or from special purpose "sleet locomotives."

Compounds used for rail de-icing are either water-soluble freezing point depressants, or waterrepellent adhesion reducers, or a combination of both. In the first group proprietory and domestic mixtures which have been used have been variously compounded of glucose, dextrin, sodium chloride, reducing sugars, sodium nitrate, glycerol, ethylene glycol and sodium acetate, with additions for thickening, thinning or spreading as necessary. The second group comprises waterrepellent adhesion reducers such as special mineral oils. A third group of dual purpose de-icing liquids consist mainly of glycol, and mineral oils, wool grease and glucose.

The extent to which the de-icing provisions described now provide a complete answer to icing interference with top contact third and fourth rail electric traction systems is not certainly established. Every several years a glazed frost of severity occurs when perhaps rain falls on freezing ground, or a thaw is checked, or ice is formed by local condensation on to current rails below freezing point. A thin film of de-icing fluid a few thousandths of an inch thick can dispel hoar frost but clearly cannot dispel an ice coating of more than say $\frac{1}{8}$ in. $(3.2 \mathrm{~mm}$.) thickness. Its value in reducing the adhesion of such an ice coating must be the subject of more experience in the field before the value of existing de-icing techniques in the freak conditions which characteristically occur only once in several years can be predicted with certainty.

In using de-icing precautions London Transport and Regions of the Railway Executive are guided by a weather forecasting service specially provided for them by the Meteorological Office. The form of the bulletin supplied and a scale of icing risk utilized have been the subject of joint discussion between the railway staff and the meteorologists. Arising from these talks, and in order to augment available data by which weather quantities may be correlated to icing conditions embarrassing to electric railways, an arrangement has been concluded between London Transport and the Meteorological Office whereby hydrographs and thermometers fitted with remote recording gear have been installed at Barons Court, in West London. Humidity, air temperature and rail temperature are automatically and continuously recorded and observers are posted as necessary to note the nature and adhesion of icing deposits formed on a test section of rail.

The installation was completed too late in the winter of $1949-50$ to yield conclusive data, but as a pilot meteorological post it has proved quite satisfactory. It is hoped that in due course the information supplied by this and other similar posts will enable the forecasters to work on the basis of both local and general data affecting the icing risk to electric railways which are not now available.

\title{
ICING IN COLD STORES
}

\author{
By G. G. Lilley, B.A.(Mech. Sc.), A.M.Inst.R. \\ (Armstrong Cork Company)
}

IT is proposed here to examine three sets of conditions in the cold storage industry where ice formation is harmful, together with possible solutions.

I. Ice formation on the inside surfaces of cold rooms and more especially on airlock walls

Let us consider a typical layout consisting of two sub-zero cold stores at say $-15^{\circ} \mathrm{F}$. $\left(-26^{\circ} \mathrm{C}\right.$. $)$ separated by a smaller airlock, the walls between the stores and the airlock being typically of 
4-6 in. of insulation with the remainder of the airlock insulated with 6 in. $\left(\mathrm{r}_{5} \cdot 24 \mathrm{~cm}\right.$.) of insulation (see Fig. I, p. 544).

It is often found in practice that the walls dividing the airlock from the stores become sheeted with ice; during periods of defrosting or if for some other reason the airlock becomes warmed, part of this may melt, but frequently refreezes on the floor. Not only is the result dangerous for those working in the store, but also the presence of ice on the wall finish is liable to aggravate cracking, since it will tend to penetrate any minute cracks already present and enlarge them. Wall ice also, of course, hampers the operation of doors, switches and any other fittings fixed to the walls.

Fig. 2 (p. 544) shows in detail the conditions near the surface of such a dividing wall. In an actual example, the air temperature near the surface wall on the airlock side was found to be $28^{\circ} \mathrm{F}$. $\left(-2 \cdot 22^{\circ} \mathrm{C}\right.$. $)$. Using the concept of thermal resistance as the reciprocal of conductance and taking a value for the surface film cofficient as $0.5(0.103)$ with an insulation resistance of $20(4 \cdot \mathrm{I})$ which is based on an insulation conductivity of $0.3(0.037)$ and thickness 6 in. $\left(15^{.24} \mathrm{~cm}\right.$.) giving a resistance of $\frac{6}{0.3}=20$, the wall surface temperature is $26 \cdot 97^{\circ} \mathrm{F}$. $\left(-2 \cdot 79^{\circ} \mathrm{C}\right.$.), a drop of $\mathrm{x} \cdot 03^{\circ} \mathrm{F}$. $\left(0.57^{\circ}\right.$ C. $)$.

Units of resistance are ${ }^{\circ} \mathrm{F} . \mathrm{Ft} .{ }^{2} \mathrm{Hr} . / \mathrm{B} . \mathrm{Th} . \mathrm{U} .\left({ }^{\circ} \mathrm{C} . \mathrm{M} .{ }^{2} \mathrm{Hr} . / \mathrm{Kg}\right.$. Cal.) and of conductivity B.Th.U. in. $/{ }^{\circ}$ F. Ft. ${ }^{2}$ Hr. (Kg. Cal. M. $/{ }^{\circ}$ C. Hr. M. ${ }^{2}$ ).

If air at $28^{\circ} \mathrm{F} .\left(-2 \cdot 22^{\circ} \mathrm{C}\right.$. $)$ is to avoid depositing ice on a surface at $26.97^{\circ} \mathrm{F}$, then it must have a relative humidity of approximately 95 per cent or less. In fact, if ambient air at say, $55^{\circ} \mathrm{F}$. $\left(12.3^{\circ} \mathrm{C}\right.$.) and 75 per cent relative humidity is cooled to $28^{\circ} \mathrm{F}$., it will have a humidity of roo per cent and will have deposited appreciable proportions of moisture and ice during cooling $\left(0.003^{8}\right.$ lb. per lb. (0.0038 gm. per gm.) of air approximately). Moreover, for as long as the air change due to door openings and the moisture gain from operatives is sufficient to maintain this relative humidity above 95 per cent, for so long will ice be deposited. In practice, this amounts to the whole of a normal day's working.

It is almost impracticable in a normal cold store in daily use so to restrict door openings that the airlock humidity will, by deposition on wall surfaces, fall below 95 per cent and so cease, but obviously one of the first steps to reduce the volume of ice formation is to reduce the rate of air change. In order absolutely to prevent deposition, the wall surface temperature must be raised as near to the air temperature as possible, whilst the relative humidity must be lowered, until no surfaces are at or below dew-point temperature.

Increasing the insulating value of the wall will certainly raise the warm surface temperature of the wall. It will also, of course, raise the air temperature and unless ridiculously thick walls are used (thicker than the walls dividing the cold rooms from the ambient air) it will not ensure a surface above dew-point temperature. It can, however, raise the surface above freezing point, although with the layout shown the area for heat gain in the airlock is small and over a period its temperature gradually falls to values near freezing point, even when $8 \mathrm{in}$. $(20.32 \mathrm{~cm}$.) of insulation are used. Nevertheless, a suitable balance can be found by reducing or even omitting insulation on the walls and ceiling dividing the airlock from the ambient air, and so increasing the effective heat pick-up.

Unfortunately, modern practice is tending towards colder airlocks which are frequently used for the storage of containers, etc., which it is useful both from the thermal and bacteriological point of view to keep as cold as possible.

To achieve this with a layout as shown, it is common practice to extend several turns or even whole grids from the cooling coils in the stores, through the partition wall and so to form wall or ceiling coils in the airlock. Typical temperatures under such airlock conditions are $16^{\circ}-$ $20^{\circ} \mathrm{F}$. $\left(-8.9^{\circ}\right.$ to $-6 \cdot 7^{\circ} \mathrm{C}$.). Most coil arrangements relying on natural air circulation, are designed 
to maintain as high a humidity as possible, and they are enabled to do this because of the very slow air movement which they set up. This air movement is insufficient to pass large quantities of air over the pipe surfaces and although moisture is extracted and deposited as ice on the coil surfaces, insufficient is removed to compete with the moisture gain from door openings, operatives, etc. The new temperature balance is slightly more favourable to the wall surface conditions than before. For example, using the same figure as before with the exception of the airlock temperature which is now taken as $20^{\circ} \mathrm{F}$., the surface temperature will be $19^{\circ} 16^{\circ} \mathrm{F}$. $\left(-7 \cdot 13^{\circ} \mathrm{C}\right.$.) or $0.84^{\circ} \mathrm{F}$. $\left(0.46^{\circ} \mathrm{C}\right.$.) below air temperature. This is a smaller temperature drop than before, but it still requires a relative humidity of 95 per cent or less to prevent deposition, owing to the lower air temperature.

When cooling the air in the airlock from $28^{\circ}$ to $20^{\circ} \mathrm{F}$., approximately $0.00 \mathrm{I} \mathrm{lb}$. of ice per lb. (०.00I gm. per gm.) of air will be deposited in excess of the amount originally deposited in the uncooled airlock, and while the coils do carry some ice as already stated, the amount carried is quite inadequate to reduce the humidity appreciably below roo per cent, especially bearing in mind this added duty. In addition, now that all the air in the airlock is below freezing point, the floor surface temperature falls below freezing point and the slow movement of saturated air over this cold surface results in a build up of ice on the floor.

Under the conditions now imposed, increase in insulation will be useless, that is, within economic and practical limits, and other means must be adopted.

One way to raise the wall surface temperature would be to reduce its surface coefficient of thermal resistance. This coefficient depends mainly on the texture of the surface and the speed of the air over the surface. Assuming a cement rendering float finished, an air speed of approximately $400 \mathrm{ft}$. $/ \mathrm{min}$. ( $12 \mathrm{I} .9 \mathrm{~m} . / \mathrm{min}$.) will, according to graphs published by the American Society of Heating and Ventilating Engineers give a surface coefficient of approximately 0.25 , or half the previous value. This reduction will almost exactly halve the temperature drop, giving $0.515^{\circ} \mathrm{F}$. $\left(0.275^{\circ}\right.$ C. $)$ drop for the unrefrigerated airlock at $28^{\circ}$ and $0.42^{\circ} \mathrm{F}$. $\left(0.23^{\circ} \mathrm{C}\right.$. $)$ for the coil cooled airlock at $20^{\circ} \mathrm{F}$. To avoid deposition of ice at these temperatures, the relative humidity must not exceed a value of $97-98$ per cent in each case.

Now where an uncooled airlock is being considered, provided the rate of door opening is not high, it may be possible to maintain the humidity below 98 per cent and it will be possible to avoid ice deposition on specific areas such as door surfaces by arranging a fan to draw air across these surfaces at the speed indicated. This has in fact been done with some measure of success.

In a refrigerated airlock the problem becomes even more simple of solution, since not only can the air be circulated over the walls, thus reducing their surface coefficient, but it can be circulated over the coils at a rate sufficient to ensure that all the air in the airlock can pass over the coils several times in an hour.

It is suggested that in practice, provided the rate of air flow over the coils is some ten or twenty times the rate of air change due to door opening, this will be quite sufficient to extract all the additional moisture admitted and to keep the humidity below 97 per cent. The rate of air change is unlikely to exceed one complete change per hour unless conveyors pass through the wall; assuming a roo cu. ft. airlock, therefore, the rate of flow required is ro,000-20,000 cu. ft. $/ \mathrm{hr}$. $(5-10 \mathrm{~m} .3 / \mathrm{m}$.) -approximately $\mathrm{I} 70-340 \mathrm{cu}$. ft. $/ \mathrm{min}$. (300-600 $\mathrm{m} .3 / \mathrm{min}$.).

Exact measurements of the air flow and humidites resulting from such a system are not available, but it has been found that quite a small fan and small coil area will result in a dry and icefree airlock. The coils should, of course, operate at as low a temperature as is practicable-this will normally be the same as the coils in the main store; they will also require adequate defrosting arrangements.

In the case of a main room cooled by ducted air that has been circulated over a separate air cooler battery, the problem becomes quite simple if tackled at the design stage, and in fact, for 
rooms running as low as $-15^{\circ} \mathrm{F} .\left(-26 \cdot \mathrm{I}^{\circ} \mathrm{C}\right.$. $)$ air locks-or more properly, air-temperature locks-are in operation with quite remarkable success.

\section{Ice formation on the sealing surfaces of cold store doors}

This ice formation must be distinguished from that forming on the face of a door under the conditions already examined for walls, since in extreme cases such as air blast freezers and other
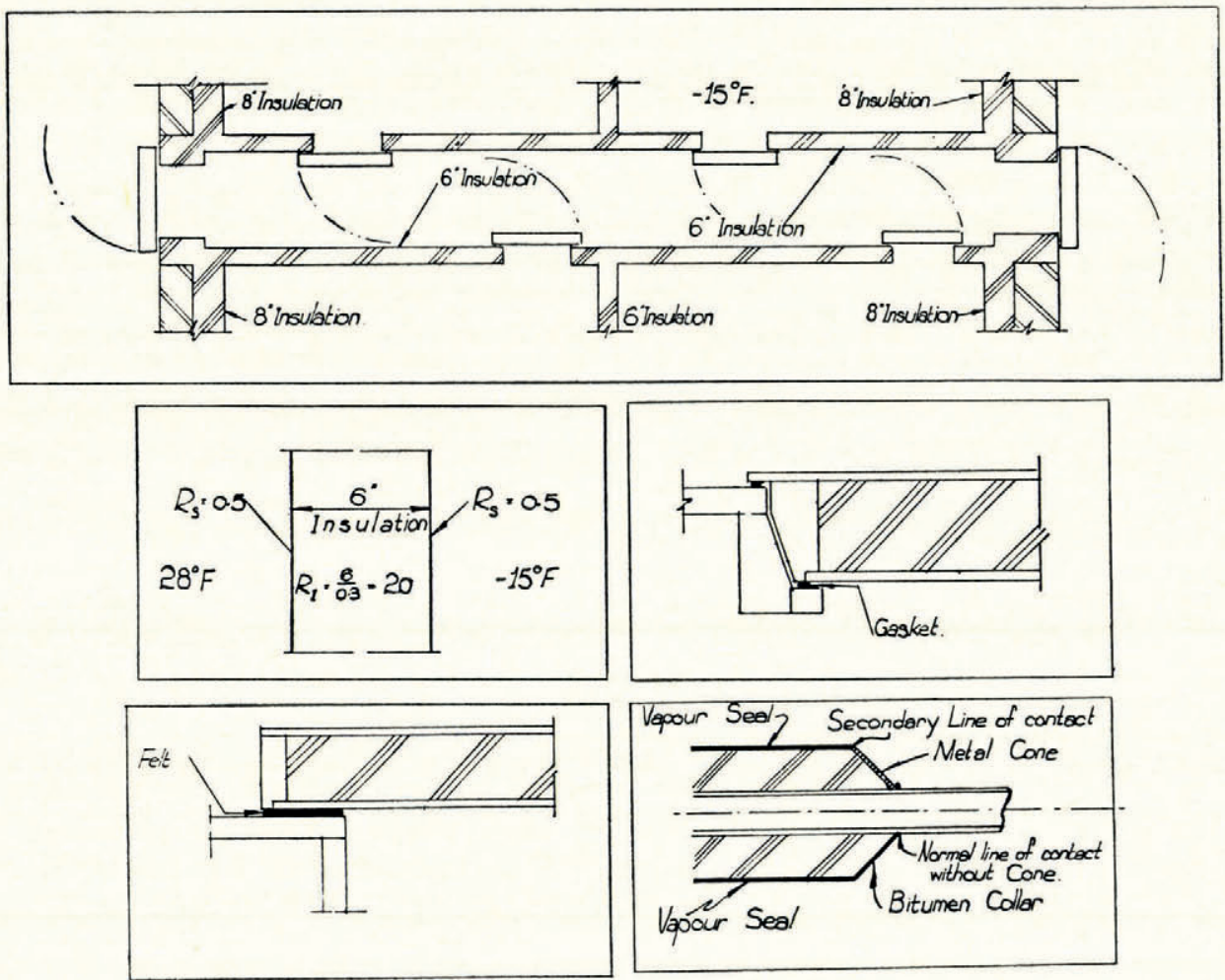

Fig. I (top) see text p. $54^{2}$

Fig. 2 (middle left) see text p. $54^{2}$

Fig. 3 (middle right) see text below

Fig. 4 (bottom left) see text below

Fig. 5 (bottom right) see text p. $54^{6}$

low temperature operations at $-25^{\circ} \mathrm{F} .\left(-31: 7^{\circ} \mathrm{C}\right.$.) and below, even when no ice forms on the outer face and edges of a door, trouble can be caused by icing between the sealing surfaces of the door and its frame.

Low temperature cold store doors are divided into two main types. One consists of a rebated door seating on two or more gaskets which form one or more line seals and leave an air space between the gaskets of the door and its frame (Fig. 3, above).

The other type consists of a door which overlaps its frame and seals against a broad band of felt or similar soft material, some $4^{-6}$ in. wide; here there are no air spaces (Fig. 4, above).

In the first type, on opening the door, the inside face of the door and its gaskets swing back into the warmer air of the airlock and a thin film of ice is deposited; on reclosing the door some of the warmer air is trapped between the inner and outer gaskets and as this is cooled more ice is 
deposited. After repeated opening and closing of the door, this build up of ice is sufficient to interfere with the efficiency of the seal. As soon as this happens, the build up of ice is greatly accelerated and the door becomes difficult to close and even more difficult to open. In this latter connection, the practice of using crowbars to break the adhesion of the ice does nothing to improve the life or fit of the average door.

In the second, or overlap type of door, with area contact between the sealing faces, the initial build up of ice is limited to that deposited on opening the door, since there is no air space present to trap warm moist air.

For this reason, the period of efficient operation before the ice must be scraped off is lengthened, but the performance is not always satisfactory under very severe conditions. Both types of doors can be made to operate under severe conditions by a similar method, although on a slightly different principle.

First, in a modification of the double seal door, a scheme was set out in Modern Refrigeration (20 October 1949, p. 245) for running one or more electric wires inside the air space, these wires being fed through a transformer. Control is effected by a thermostat which maintains the air space above freezing point; with a room temperature of $-10^{\circ} \mathrm{F} .\left(-23.3^{\circ} \mathrm{C}\right.$.) and an ambient of $70^{\circ} \mathrm{F}$. $\left(2 \mathrm{I} \cdot \mathrm{I}^{\circ} \mathrm{C}\right.$. $)$ a $200-$ watt tapping was required.

Secondly, in the overlap type of door, a similar scheme has been evolved where uninsulated wires are run in grooves in the frame over the area of contact. The grooves are then filled with an electrical insulator and the area covered with a metal plate against which the door seals. A thermostat control in the frame switches low voltage current to the wires through a transformer on the frame, and it has been found that for a door of $6 \mathrm{ft} .6 \mathrm{in} . \times 3 \mathrm{ft} .(\mathrm{I} \cdot 98 \times 0.9 \mathrm{I} \mathrm{m}$.) clear opening, an input of approximately 60 watts will maintain an ice-free seal, with a room temperature of approximately $-15^{\circ} \mathrm{F} .\left(26 \cdot 1^{\circ} \mathrm{C}\right.$. $)$ and ambient of about $65^{\circ} \mathrm{F}$. $\left(17 \cdot 2^{\circ} \mathrm{C}\right.$. $)$.

In this method, it is the actual sealing surfaces which are warmed, and there is no air space to heat. It is probable that certain areas of the seal under this method are still below $32^{\circ} \mathrm{F}$, , but the fact that the area of the seal is warmer than its surroundings would cause any ice formed to sublime away to the colder surfaces.

It must be emphasized that if conditions are not too severe it is possible to have doors which operate adequately, provided the humidity in the airlock is not too high, and in these cases if wall icing is prevented, icing on door seals may not be serious. By electrical heating of the seal areas, however, doors have been operated successfully even when the airlocks were sheeted with ice.

\section{Ice formation on metal or other materials of high thermal conductivity where these penetrate
insulation}

Ice forming at the junction of a metal-insulation surface is liable to creep beneath the insulation and split it off owing to the great difficulty experienced in maintaining a tight joint not likely to crack. This is perhaps the most difficult problem to solve of the three under consideration, and so far no generally acceptable solution has been found, much less adopted, although there are individual solutions.

In the first place, where a structural member penetrates through the outer insulation of a cold store, this will form a source of heat leakage and possible ice formation. Here, however, unless space is restricted, it is usually possible to carry a sleeve of insulation along the member until the temperature gradient established results in the junction of outer insulation surface to metal being above freezing point.

When no sleeve is possible, as with short steel feet supporting a vessel at low temperature, a combination of a heavy density and moderately good insulating pad with local heating can be effective. 
Where, however, the insulation to metal surface joint is that point on a refrigerant pipe where the insulation ceases - for instance, near the compressor or around a valve spindle, it is not possible to keep the metal ice free actually on the normal line of contact. It has been suggested that by arranging for a false or secondary line of contact, ice formation can be avoided (Fig. 5, p. 544).

Here the cone of metal must be sufficiently large to pick up enough heat, so that the new line of contact is above freezing point and considerable research would be needed to arrive at the correct areas of heat pick up for varying pipe and ambient temperatures.

\section{ICING PROBLEMS ON SHIPS \\ By F. S. SUTHERBY, R.C.N.C., M.I.N.A. \\ (Department of Naval Construction, Admiralty)}

THE following remarks are derived mainly from the experiences of ships of the Royal Navy serving in Arctic waters. Icing was encountered by our submarines operating in the Baltic Sea in the 1914-18 war and by the warships of all types which crossed the Greenland and Barents Seas as escorts or covering forces for North Russian convoys in $194 \mathrm{I}-45$, but in peace the phenomenon may still be encountered in any winter by the ships of the Fishery Protection Flotilla or the frigates on the America and West Indies Station. A certain amount of experience of icing is also gained during special cruises; for example, by the ships participating in the Cold Weather Cruise in February 1949. These experiences, however, merely display in somewhat heightened form the problems which confront any steel ship in high latitudes.

In point of fact, in the Cold Weather Cruise of 1949 far more rough weather was encountered than cold weather, and heavy icing never occurred. This seems to be fairly typical of experience in near-Arctic regions, which can be traversed time after time without experiencing icing. The weather conditions which give rise to this phenomenon are a strong wind, a cold sea, say $29^{\circ}$ to $32^{\circ} \mathrm{F}$. $\left(\mathrm{I} \cdot 7^{\circ}\right.$ to $0^{\circ} \mathrm{C}$.), and a low air temperature, say $5^{\circ}$ to $20^{\circ} \mathrm{F}$. $\left(-15^{\circ}\right.$ to $-6.7^{\circ} \mathrm{C}$.). Incidentally, these air temperatures are low for the open sea clear of land masses or ice. In strong winds continuous masses of cold spray are flung at the ship at a temperature just above freezing point ; the low air temperature chills the steel and the spray freezes immediately on impact. With these conditions a film of ice builds up on the steel. This tends to become a sheet and the sheet a block. There is no apparent limit to the process, which continues while the weather conditions persist. In general the ice formed in this way binds tenaciously to the steel. If an opportunity comes to remove the ice a considerable physical effort with ice picks and similar implements is required.

All the above-water parts of the ship which are not perceptibly warm are liable to accumulate ice when the weather conditions are suitable. In time the weather surfaces of the ship and its superstructure and deck equipment disappear under the icy envelope. This has two effects:

(a) The deck equipment will, in the absence of special measures, become locked with ice and unworkable; and

(b) The weight of ice which is being continuously added to the topsides of the ship will reduce and may even endanger the stability of the ship.

The effect of icing on the superstructure of a ship is thus a progressive wearing down of the resistance of the ship to capsizing. In a beam wind one side of the ship would be iced and the ship would heel to that side, and, with the deck edge brought nearer to the waves, the rate at which ice is deposited would be accelerated. 